\title{
EFFECT OF NOZZLE SHAPE AND PRESSURE ON DROPLET SIZE DISTRIBUTION
}

\author{
El-Berry, A. M., Ramadan M. Hany², El-Adl A. Mohsen³ and \\ Mahmoud M. Hashem ${ }^{4}$
}

\begin{abstract}
Droplet size data from the sprinkler (R.C. 160-S) fitted with nozzles shapes square, rectangle, triangle and circle were studded in this work. A total 48 indoor tests were conducted. The pressure range was between $138 \mathrm{kPa}$ (20psi) and $241.5 \mathrm{kPa}$ (35psi) at $34.5 \mathrm{kPa}$ (5 psi). Droplet size diameters were measured using the immersion method and Image Pro software. Nozzle pressure and shape had a major influence on droplet size. Higher pressure promoted smaller droplets over the entire application profile especially near the perimeter. Generally, the mean droplet sizes was larger for noncircular nozzles at a given distance from the sprinkler, but circular nozzle produced the largest droplet size at the outer perimeter of the pattern, that's because of long throw of circular nozzle than noncircular.
\end{abstract}

Key wards: sprinkler, noncircular, nozzles, low pressure, droplet size.

\section{INTRODUCTION}

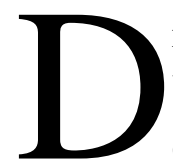
roplet size is influenced by nozzle characteristics and pressure. Volume weighted means diameter is proportional to nozzle diameter and is inversely proportional to pressure. Pressure effect on circular nozzle has greater influence on droplet size distribution Kohl, (1974). He also studies the effects of pressure and nozzle size on the drop size distribution from medium-size agricultural sprinklers.

Results of similar experiments by Kincaid et al. (1996) agreed with these of Kohl (1974). The effect of the nozzle size on sprinkler is smaller than pressure effect.

1 Prof of Agric. Eng., Dep. of Agric. Eng. , Faculty of Agriculture, Cairo University, 2 and 3 Assoc. Prof of Agric. Eng. Dep. of Agric. Eng., Faculty of Agriculture, Al-Mansoura University, and 4 Agric. Res. Ins., Alexandria Branch, Alexandria, Egypt 
Ismail (1986) stated that the droplet size distribution of both fixed and revolving sprinklers were determined under three different operating pressures using the flour method. As the pressure increases the distribution shifts toward the smaller droplet diameters. Revolving sprinkler produces larger droplet diameters up to $4 \mathrm{~mm}$ and application rates between 3 and $10 \mathrm{~mm} / \mathrm{h}$ while fixed sprinkler produces smaller droplet diameters up to $2 \mathrm{~mm}$ and application rate ranges between 15-25 $\mathrm{mm} / \mathrm{h}$.

Hills and $G \boldsymbol{u}$ (1989) Reported that the main factors influencing the droplet size distribution with impact sprinklers are working pressure, size and shape of the nozzle. The higher the pressure, the larger the number of small size drops as a result of a higher jet velocity and the increment of the difference with wind speed. They observed that the volume mean droplet diameters for the $3.2 \mathrm{~mm}$ nozzle under different pressures varied between approximately $0.7 \mathrm{~mm}$ and $4.6 \mathrm{~mm}$. The smaller sizes generally occurred at the higher pressure and were located nearer to the sprinkler. Conversely, the larger size droplets were formed at the lower pressure and were located farther from the sprinkler.

Noncircular nozzle can be effective in low pressure operation, yielding acceptable distribution patterns Dadiao and Wallender, (1985). Noncircular nozzles have received attention because it save more energy in compared with systems using circular nozzles Jiusheng and Hiroshi, (1995).

Circular nozzles usually produced greater wetted radii and larger droplet diameters than noncircular nozzles. However, noncircular nozzles give higher overlapped uniformity coefficients. Droplet formations from noncircular nozzles were compared with those from circular nozzles and it was found that noncircular nozzles created greater portion of droplets with diameter less than three millimeters at a given pressure. It is therefore confirmed that noncircular nozzles have the advantages of providing an acceptable water application pattern and smaller portion of large droplets over the entire precipitation profile at low operating pressure. Jiusheng et al., (1994).

Kansas USA has an estimated 3.1 million acres of irrigated land with the majority using sprinkler systems. Converting from medium pressure to 
low pressure systems, the per acre energy savings could be about 9 per acre. Converting from the high-pressure systems to low pressure would result in an additional savings 41 \$ per acre. Using noncircular nozzle gives ability to use low pressure systems.

Some researchers e.g. Chen and Wallender, (1985) have shown that by diffusing the spray jet, noncircular nozzles can be effective at lower operating pressure and may gave an acceptable distribution pattern.

Jiusheng et al., (1994) reported that, droplets size and water distribution for noncircular were compared with the performance of circular nozzles. Generally, volume mean droplet sizes larger for noncircular nozzles at a given distance from the sprinkler, but circular nozzles produced the largest average droplet size at the outer perimeter of the pattern. This result was similar to that of Chen and Wallender, (1985). Noncircular nozzles produced a much greater portion of droplets with diameter less than $3 \mathrm{~mm}$ than circular nozzles with similar discharges at a given pressure, for a given nozzle discharge, the square nozzles were operated at a pressure $49 \mathrm{kPa}$ lower than circular nozzles. The square nozzles created an approximately equal, or slightly greater portion of droplets smaller than $3 \mathrm{~mm}$. So noncircular nozzles have the advantages of providing an acceptable water application pattern and smaller portion of larger droplets over the entire precipitation profile at low pressure. This was possible because wetted diameter was greater for circular nozzles.

Hall and Boving (1956) found that water distribution from jets formed by isosceles triangular orifices to be concentrated more near the outer limit of the pattern as the height to width ratio of the orifice increased. Performance agreed most nearly with their ideal distribution in the case of a 1:1 height to base ratio.

Heernann and Kohl, (1981) stated that the evaporation loss from sprinkler irrigation is taken as the difference between the amount of water leaving the nozzles of sprinkler and the amount of water measured with grid network of catch vessels. Ediing (1985) found that evaporation decreases with increasing size of droplets and lower nozzle elevation. Reducing pressure from $200 \mathrm{kPa}$ to $50 \mathrm{kPa}$ reduced evaporation losses about 1 to $2 \%$ depending upon wind speed. One of the advantages of 
increasing small droplet size is to overcome problem associated with evaporation.

The objectives of this paper is to reducing the sprinkler base pressure to that limit which keeps acceptable droplet size diameter using noncircular nozzle shapes.

\section{MATERIALS AND METHODS}

Sprinkler tests were conducted indoors. The electric pump used in the study was a centrifugal pump $0.37 \mathrm{~kW}$ with $3 / 4$ inch inlet diameter and $3 / 4$ inch outlet diameter. The pipe line used was polyethylene pipe of $3 / 4$ inch nominal diameter. The riser height is $100 \mathrm{~cm}$. It was steel pipe of $3 / 4$ inch nominal diameter. The sprinkler used in the study is manufactured by R.C. Farm Company in Spain with product No. R.C. 160-S. The sprinkler Material is Plastic Full circle $3 / 4$ inches male pipe threaded connection. The trajectory angle of the nozzles is $20^{\circ}$. The original orifice is a circle of $4.2 \mathrm{~mm}$ diameter. Three other orifice shapes were locally manufactured (i.e. square of $3.9 \mathrm{~mm}$, rectangle of $3 \mathrm{~mm}$ width $\times 5$ $\mathrm{mm}$ height and an isosceles with base and height of $5.5 \mathrm{~mm}$. The Petri dishes of $89 \mathrm{~mm}$ diameter and $16 \mathrm{~mm}$ height was used. An engine mineral oil local brand (i.e. Misr $10000 \mathrm{Km}$ ) was used in this study.

The droplet photographic instrument adopted illumination technique was used. It was designed and constructed as shown in Figure (2). The instrument consists of a flat backdrop of wood sheeting $45 \mathrm{~cm}$ long and a $28 \mathrm{~cm}$ width. A $70 \mathrm{~mm}$ hole was made near the center of the sheet. The backdrop sheet was supported by a wooden frame which allows the backdrop to rest above the light source by $4 \mathrm{~cm}$. A steal rod $1.5 \mathrm{~cm}$ diameter and $22.5 \mathrm{~cm}$ height was fixed $35 \mathrm{~mm}$ from the end of hole. The steel rod was used as a stand for the digital camera. The droplet photographic instrument was supplied with an electric wire of $20 \mathrm{~m}$ length enough to move the instrument among the Petri dishes in an easy and fast way. Also it was supplied with an electric switch for the light source. 


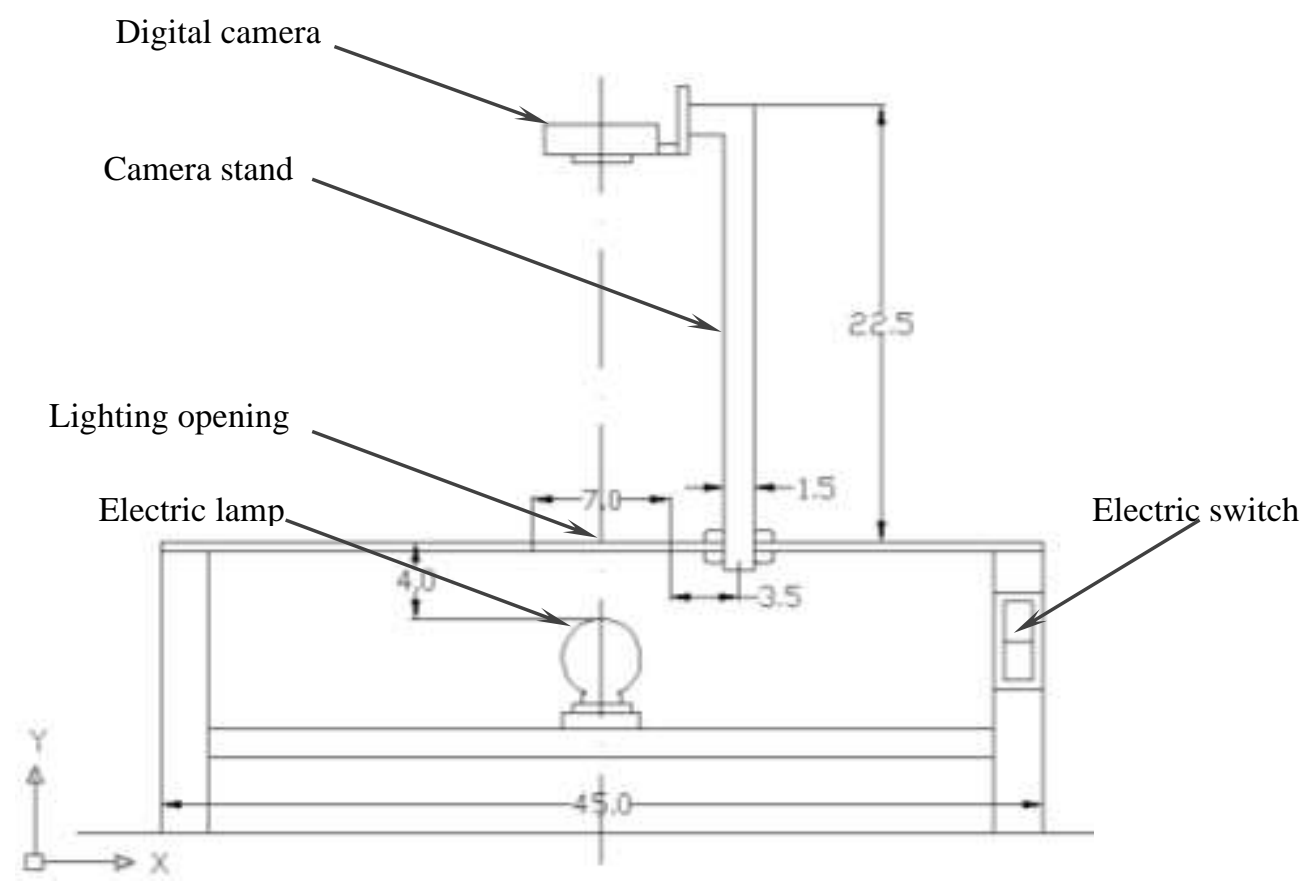

Figure (2): Schematic diagram of the droplet photographic instrument. (Dimensions. in $\mathrm{cm}$ ).

The Nicon coolpix 5600 Digital Camera was used to photo the Petri dishes with oil using the close up mode. It is 5.1 mega pixels and $3 \mathrm{X}$ zoom.

The Image-Pro Plus for windows version 1.3 Program used in this study to measure the droplet diameter from the photos of Petri dishes with oil and water droplets.

The sprinkler base pressure of 138, 172.5, 207 and $240 \mathrm{kPa}(20,25,30$ and 35 Psi respectively) were used. The pressure was measured using the dial pressure gauge 60 Psi with scale increment of 2 Psi. The pressure gauge was fixed right below the sprinkler base at $92.5 \mathrm{~cm}$ height from the lateral. The recommended standard distance should be on the riser at least 10 times diameter downstream from any change of direction of flow or change in pipe cross-sectional, ASABE standard (2006).

A total of 48 experiments were carried out (i.e. 4 pressure levels $\times 4$ orifice shapes $\times 3$ replicates).

\section{Pre experiment:}


The volume mean weight diameter method was used to determine the actual droplet size diameter (ADSD). The ADSD was correlated to the measured droplet size diameter (MDSD). The following formula was concluded.

$$
\mathrm{ADSD}=0.9988 \mathrm{MDSD}+0.0244 \quad \mathrm{R}^{2}=0.99
$$

Since the slope 1 almost one and the intercept is close to zero, the ADSD was considered equal to MDSD in this study.

\section{Measuring droplet diameter:}

The oil immersion method Nawaby, (1970) and Eigel and moore, (1983) was used to determine the droplet size diameter. The Petri dishes of this method were $89 \mathrm{~mm}$ in diameter and $16 \mathrm{~mm}$ in height. The oil type was used in this study is an engine mineral oil local brand (i.e. Misr 10000 $\mathrm{Km}$ ). The sprinkler was left to make only one revolution over the Petri dishes. This, in less than 1 minuet photos was taken starting from the perimeter and ending with the nearest dish to the sprinkler. The reason for this preference is that the larger droplet size takes short time to reach the Petri bottom dish. This is an important consideration because drops that settle to the bottom of the Petri dish quickly become distorted.

The mineral oil was prepared in $1000 \mathrm{ml}$ beakers over medium heat (approximately 60 to $80^{\circ} \mathrm{C}$ ) in order to enable any entrapped air to escape from the mixture. The removal of air entrapped within the mineral oil is very important as the images of air bubbles and water drops on the photograph are indistinguishable. As the mineral oil warms it is stirred and heat is applied until no air bubbles are visible Eigel and moore, (1983).

After sufficient cooling, the mineral oil was carefully poured into the Petri dishes. Each is filled to a level approximately 2 to $3 \mathrm{~mm}$ below the rim of the dish to ensure that the oil is deeper than the diameter of the largest drop to be measured. Any air bubbles produced in this process are removed with a needle and syringe. Then the Petri dishes with mineral oil were ready for immediate use at the onset of a precipitation event. During the precipitation event the droplets were watched to check if they are liable to split up more than one or pond into two or more together. 
Petri dishes with mineral oil were putted over a wooden frame of $100 \times 100 \times 90 \mathrm{~mm}$ to avoid the splashed water from the floor to the Petri dish again. The distance among Petri dishes along the throw was $2 \mathrm{~m}$ except the nearest one it was $1 \mathrm{~m}$ (Figure 3) to collect the water droplet when the system is in steady state condition.

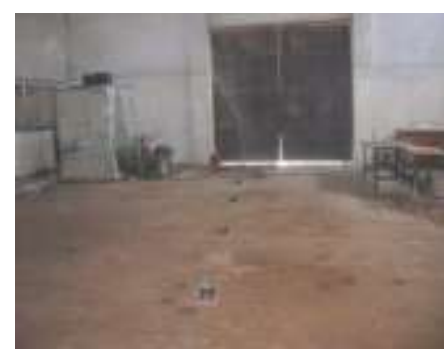

Figure (3): Petri dishes during water the precipitation event.

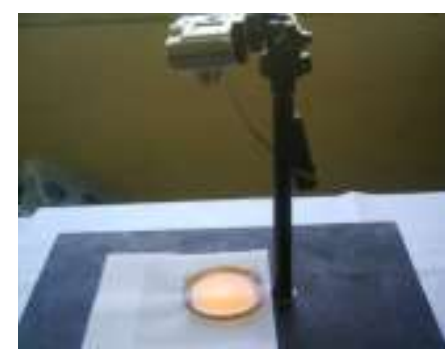

Figure (4): Petri dish during

taken photo.

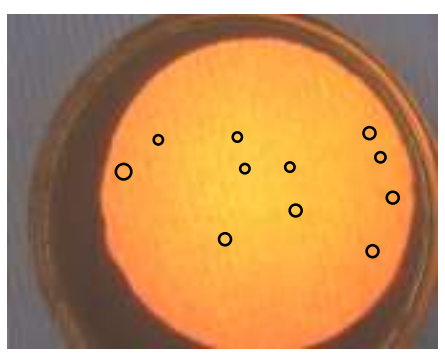

Figure (5): The photo of

droplet in imagepro.

After exposure to precipitation the Petri dishes were placed over the hole at the backdrop and photographs of the dishes were taken. A known scale mesh was placed under the Petri dish, to quickly determine the scale of the photographed droplet image when projected on the screen using Image-pro software as shown in Figure (4). It should be noted that all surfaces of the backdrop and frame were painted flat black to reduce reflections.

The images were downloaded to the computer and droplet diameters were measured using the image-pro software. One of the images is shown in Figure (5)

\section{RESULTS AND DISCUSSIONS}

\section{Effect of sprinkler base pressure on droplet diameter:}

Droplet diameter as related to pressure and distance from sprinkler was shown in Figure (6), (7), (8) and (9) for circle, square, rectangular and triangular nozzles respectively. Droplets diameter were increase with increasing distance from sprinkler but it will decrease with increasing sprinkler base pressure for all nozzles shape.

Figures 6, 7, 8 and 9 show the average droplet size diameter collected along the throw as affected by the sprinkler base pressure for the different 
orifice shapes. For all tested orifice shapes (circle, square, rectangle and triangle) the trend was similar. The average droplet size diameter collected increase as the distance from the sprinkler along the throw increase. Regarding the pressure effect, the lower the sprinkler base pressure, the higher the average droplet size diameter were obtained.

The droplets size diameter for the circular nozzle under different pressures varied between approximately $0.26 \mathrm{~mm}$ and $3.76 \mathrm{~mm}$. The smaller sizes generally occurred at the higher pressure and were located nearer to the sprinkler. Conversely, the larger size droplets were formed at the lower pressure and were located farther from the sprinkler.

Pressure had little effect on the mean droplet size diameter at $1 \mathrm{~m}$ (near the sprinkler), since it's values ranged from $0.37 \mathrm{~mm}$ at $138 \mathrm{kPa}$ to 0.26 $\mathrm{mm}$ at $241.5 \mathrm{kPa}$ with difference in diameter $(\Delta \mathrm{D}) 0.11 \mathrm{~mm}$ for circle nozzle shape as shown in Figure (10). At the greater distances, the effect of pressure was quite significant. For example, as shown in Figure (10) at $11 \mathrm{~m}$ distance from sprinkler the average droplet diameter ranged from $3.76 \mathrm{~mm}$ at $138 \mathrm{kPa}$ to $2.04 \mathrm{~mm}$ at $241.5 \mathrm{kPa}$ with difference in diameter $(\Delta \mathrm{D}) 1.72 \mathrm{~mm}$. The same result for noncircular bore nozzle are shown in Figures (11), (12) and (13) for square, rectangular and triangular bore nozzle shapes respectively.

\section{Effect of nozzle shape on droplet size diameter:}

To compare the average droplet size diameter at each pressure level for different orifice types Figures (14), (15), (16) and (17) were produced. The droplet diameter trends are the same for circular and noncircular nozzles, but at a given distance from the sprinkler, droplet diameter was larger for noncircular nozzles than for circular nozzles. The maximum droplet diameters were greater for circular nozzles than droplet diameters for noncircular nozzle near the perimeter of the wetted pattern. This is possible because the wetted diameter is greater for circular nozzle. The soil damage hazard from large droplets is further compounded in the case of circular nozzles at low pressure due to high application rates near the perimeter. 


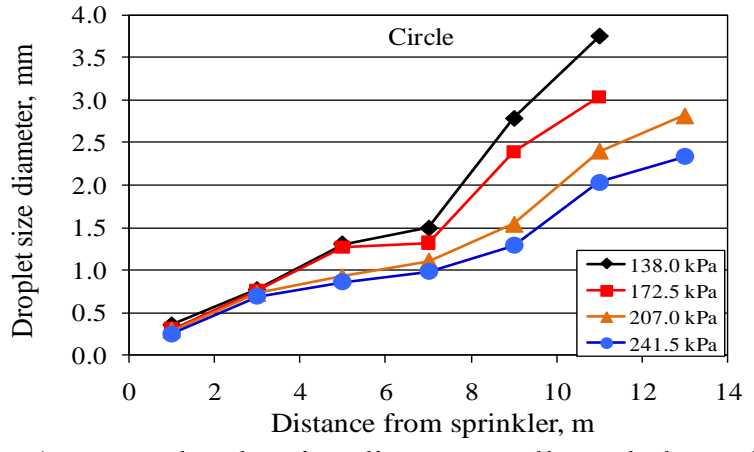

Figure (6): Average droplet size diameter collected along the throw as affected by the sprinkler base pressure for circle shape orifice.

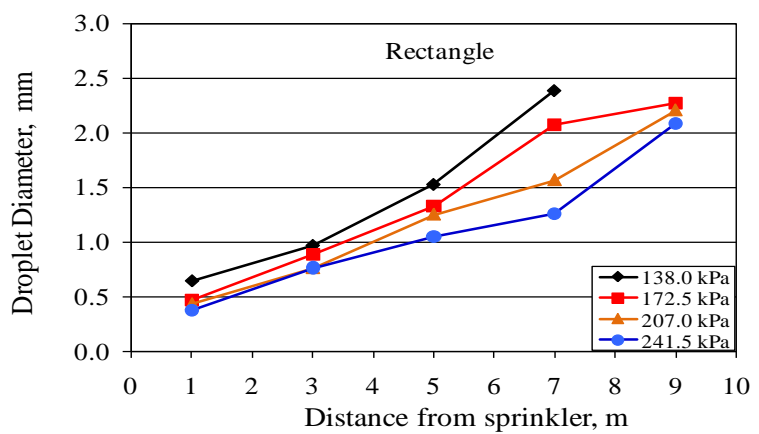

Figure (8): Average droplet size diameter collected along the throw as affected by the sprinkler base pressure for rectangle orifice shape.

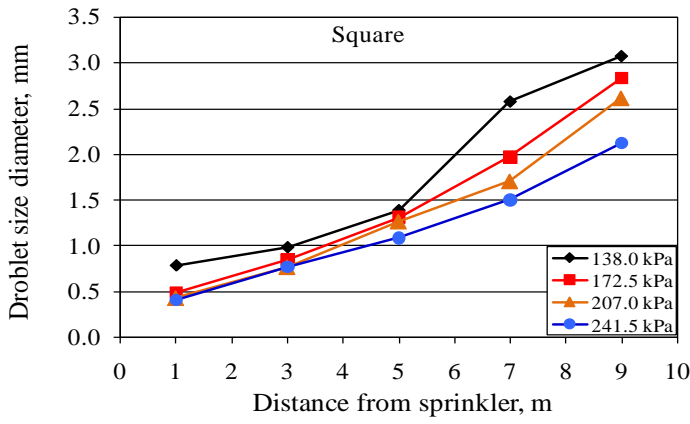

Figure (7): Average droplet size diameter collected along the throw as affected by the sprinkler base pressure for square shape orifice.

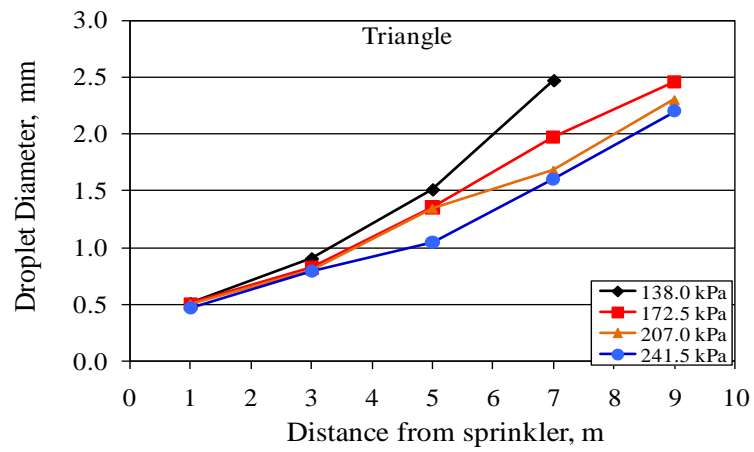

Figure (9): Average droplet size diameter collected along the throw as affected by the sprinkler base pressure for triangle orifice shape. 
Using noncircular orifice nozzle increases the minimum droplet diameter at shorter distances as shown in Figure (18). This may be useful to reduce drift and evaporation losses. Meanwhile, the maximum droplet diameter decreases for the noncircular orifice shapes. However, decrease rate of the maximum droplet size diameter is larger than the increase rate of the minimum droplet size diameter. This would in fact reduce the soil damage occurs from larger droplets.

The domain of the droplet size diameter was smaller for noncircular orifice diameter than circular at all pressures range as shown in Table (1).

\section{Energy saving:}

Non circular orifice shapes are used to produce droplet size diameter less than $3 \mathrm{~mm}$ which is the maximum droplet to reducing soil crust. These nozzles required $148.0 \mathrm{kPa}$, while the circular nozzle required $178.0 \mathrm{kPa}$ Figure (19). Reducing operating pressure reduces energy required per unit volume (Equation 2). Using noncircular nozzles reduced the energy by $16.85 \%$. Soils which are sensitive to the crust need droplet size diameter less than $3 \mathrm{~mm}$. For those soils rectangular and triangular orifices can operate at $138 \mathrm{kPa}$ while the traditional circular nozzles may operate at $231 \mathrm{kPa}$, as shown in Figure (19). As a result the energy saving percentage reached $40.26 \%$.

$$
\mathrm{E}=\mathrm{P} \times \mathrm{V}
$$

Where:

$$
\begin{aligned}
& \mathrm{E}=\text { energy }, \mathrm{kJ} \\
& \mathrm{P}=\text { operating pressure, } \mathrm{kPa} \\
& \mathrm{V}=\text { the required volume of irrigation water, } \mathrm{m}^{3}
\end{aligned}
$$




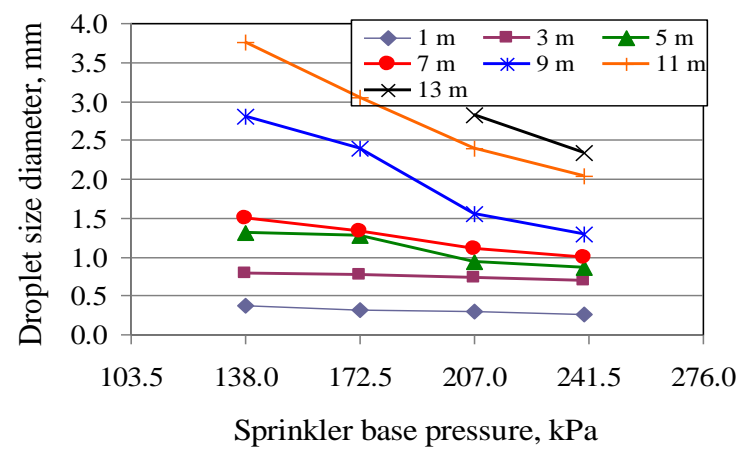

Figure (10): Effect of pressure on droplet diameter for circle orifice nozzle at different distances from sprinkler.

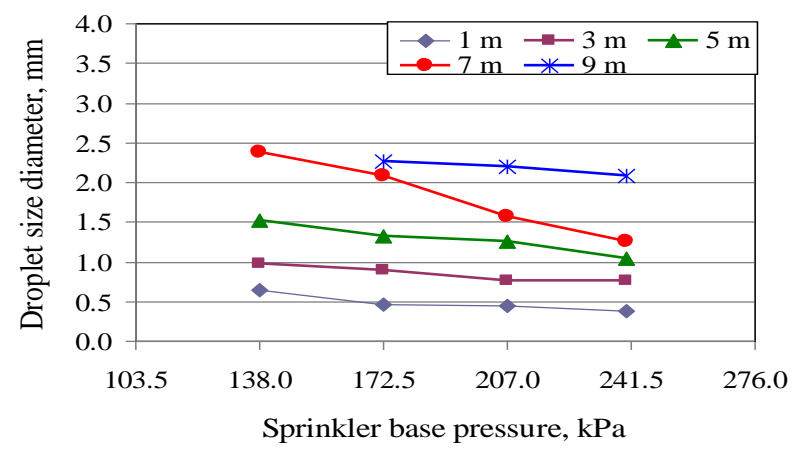

Figure (12): Effect of pressure on droplet diameter for rectangle orifice nozzle at different distances from sprinkler.

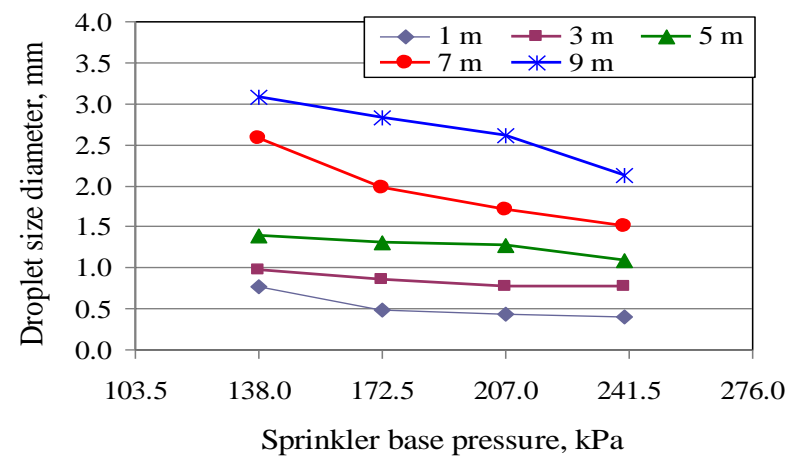

Figure (11): Effect of pressure on droplet diameter for square orifice nozzle at different distances from sprinkler.

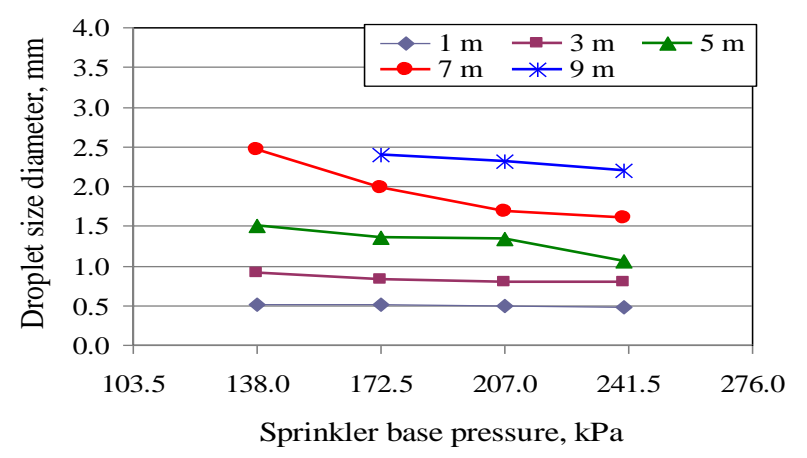

Figure (13): Effect of pressure on droplet diameter for triangle orifice nozzle at different distances from sprinkler. 


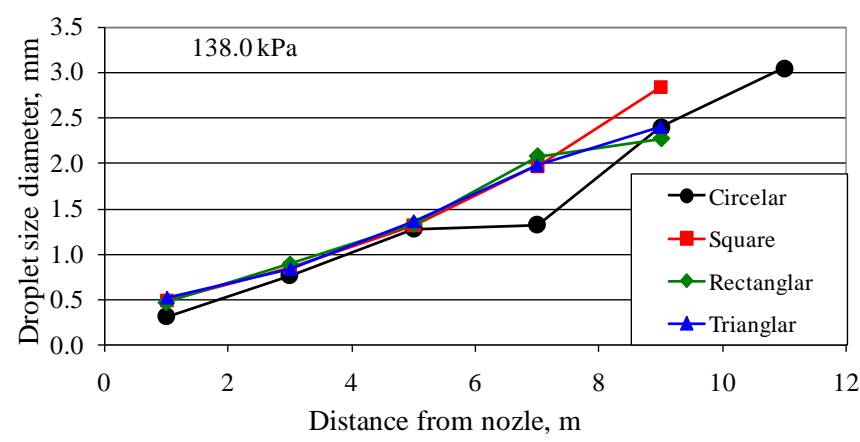

Figure (14): Effect of nozzle shape on average droplet size diameter at $138.0 \mathrm{kPa}$ sprinkler base pressure.

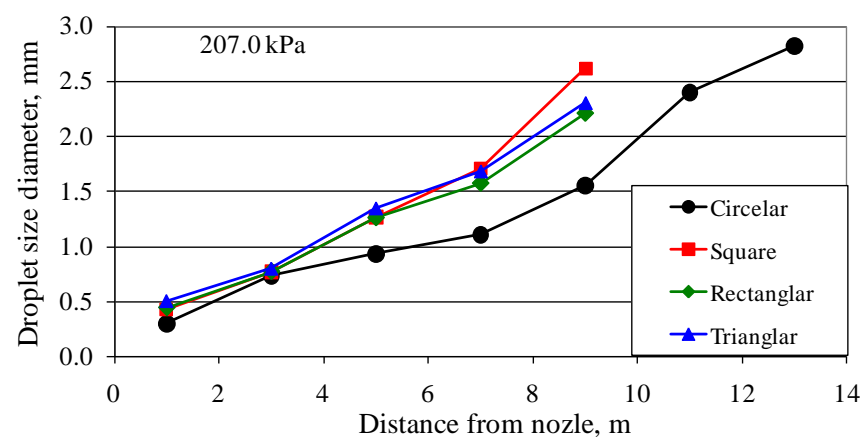

Figure (16): Effect of nozzle shape on average droplet size diameter at $207.0 \mathrm{kPa}$ sprinkler base pressure.

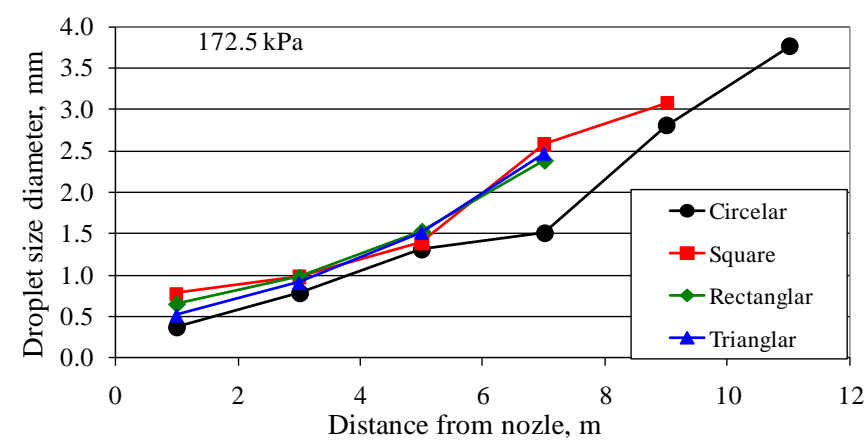

Figure (15): Effect of nozzle shape on average droplet size diameter at $172.5 \mathrm{kPa}$ sprinkler base pressure.

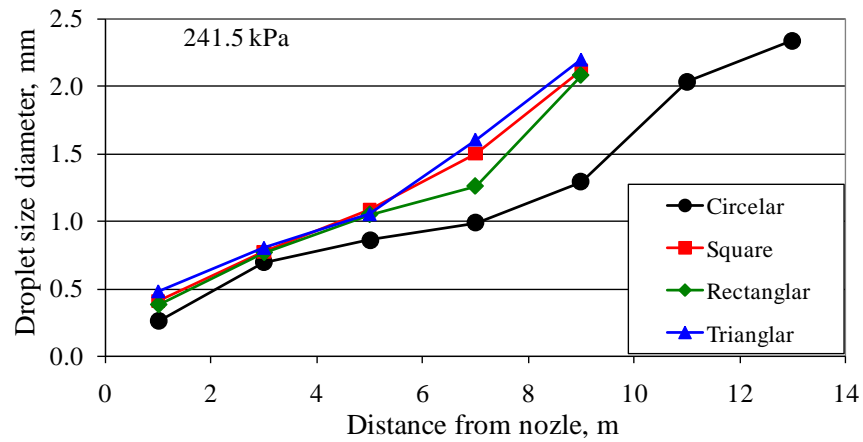

Figure (17): Effect of nozzle shape on average droplet size diameter at $241.5 \mathrm{kPa}$ sprinkler base pressure. 


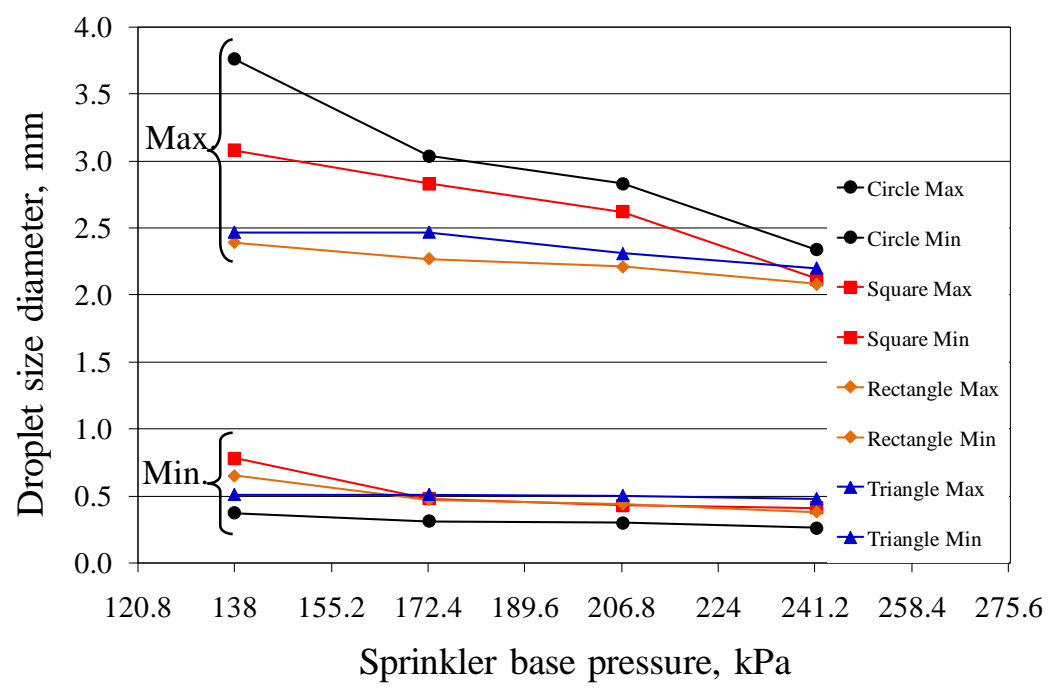

Figure (18): Effect of sprinkler base pressure on the Maximum and minimum average droplet size diameter for different orifice shapes.

Table (1): The domain of the droplet size diameter as affected by orifice shapes at different sprinkler base pressure.

\begin{tabular}{|c|c|c|c|c|}
\hline \multirow{2}{*}{$\begin{array}{c}\text { Orifice } \\
\text { shape }\end{array}$} & \multicolumn{4}{|c|}{ Sprinkler base pressure, $\mathrm{kPa}$} \\
\cline { 2 - 5 } & 138.0 & 172.5 & 207.0 & 241.5 \\
\hline Circle & 3.39 & 2.73 & 2.53 & 2.08 \\
\hline Square & 2.30 & 2.35 & 2.19 & 1.71 \\
\hline Rectangle & 1.74 & 1.80 & 1.77 & 1.70 \\
\hline Triangle & 1.96 & 1.96 & 1.81 & 1.72 \\
\hline
\end{tabular}




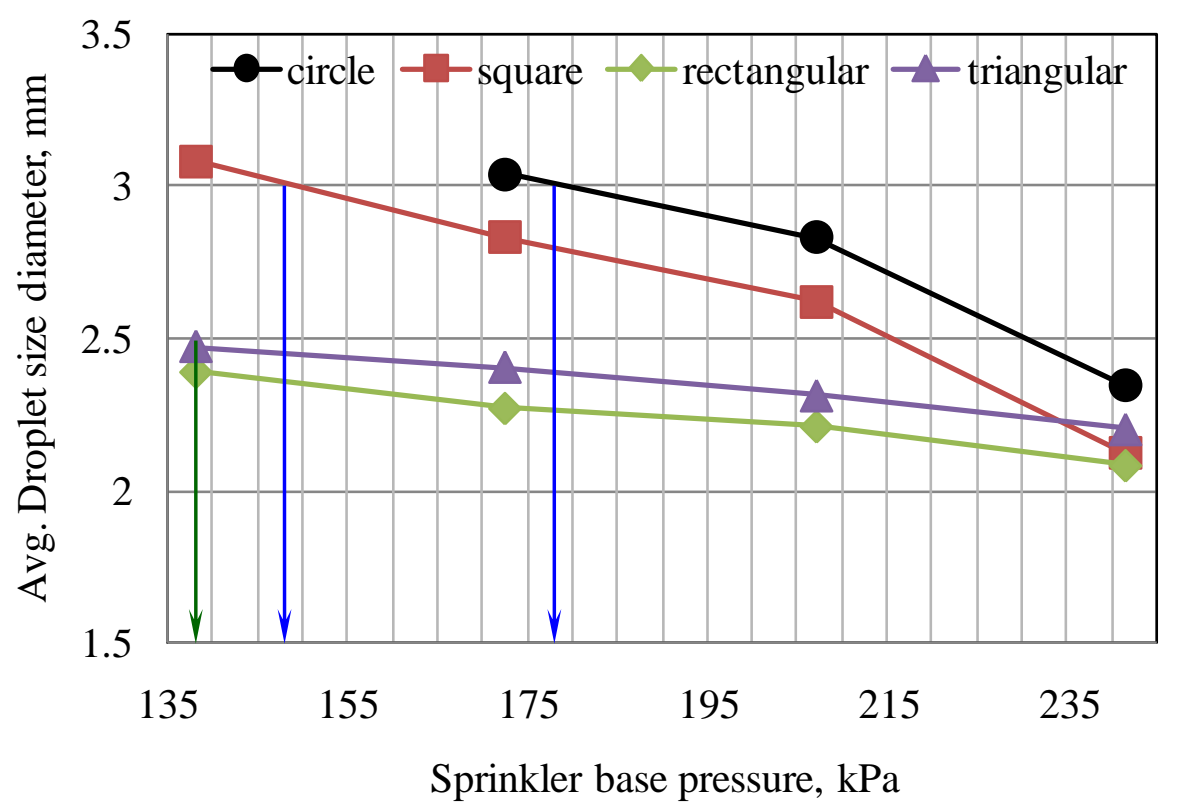

Figure (19): Effect of sprinkler base pressure on droplet size diameter for different nozzle shapes.

\section{CONCLUSIONS}

Droplet sizes for noncircular nozzles (square, rectangular and triangular) were compared with the traditional circular nozzle on low sprinkler base pressure. Generally, mean droplet sizes were larger for noncircular nozzles at a given distance from the sprinkler, but circular nozzle produced the largest droplet size at the outer perimeter of the pattern. Using noncircular orifice nozzle increases the minimum droplet diameter at shorter distances. This may be useful to reduce drift and evaporation losses. Meanwhile, the maximum droplet diameter decreases for the noncircular orifice shapes. However, decrease rate of the maximum droplet size diameter is larger than the increase rate of the minimum droplet size diameter. This would in fact reduce the soil damage occurs from larger droplets. Sprinkler base pressure is a major influence on droplet size on the fare distance from sprinkler (near the perimeter) than the droplet on the short distance (near the sprinkler). For non circular orifice the triangle nozzle shape produced the proportionally largest minimum size droplet diameter $(0.48 \mathrm{~mm})$. While, the smallest maximum size droplet diameter $(2.12$ 
$\mathrm{mm}$ ) was produced by the square nozzle shape. Increasing minimum size droplet diameter is reducing evaporation and drift losses. Decreasing maximum size droplet diameter is reducing soil damage. Using noncircular nozzles is reducing $16.85 \%$ and $40.26 \%$ of energy at maximum droplet diameter of 3 and $2.5 \mathrm{~mm}$ respectively. Generally the results recommended using noncircular nozzles for low pressure instead of circular nozzle to save power.

\section{REFERANCES}

ASABE Standards 2006. Standards Engineering Practices Data. Procedure for sprinkler testing and performance reporting. S398.1. PP 933-935.Adopted and published by the American Society of Agricultural and Biological Engineers. 53rd. Edition. ASABE, St.Joseph, MI, USA.

Chen, D.and W. W. Wallender. 1985. Droplet size distribution and water application with low-pressure sprinklers. Transactions of the ASAE 28 (2): 511-516.

Dadiao. C. and W. W. Wallender 1985. Droplet Size Distribution and Water Application with Low-Pressure Sprinklers. Transactions of the ASAE 28 (2): 511-516.

Ediing, R.J. 1985. Kinetic energy, evaporation and wind drift of droplets from low pressure irrigation nozzles. Transactions of the ASAE 28 (5): 15431550.

Eigel, J. D. I. D. Moore 1983. A simplified technique for measuring raindrop size and distribution. Transactions of the ASAE 26(4):1079-1084.

Hall, W. A. and P. A. Boving. 1956 . Non-circular orifices for sprinkler irrigation. Agricultural Engineering 37 (1) : 27-29.

Heernann, D.F. and R.A. Kohl, 1981. Fluid Dynamics of sprinkler Systems. PP 583-618 Cited from Design and operation of farm irrigation systems. 859 P. Ed. M. E. Jensen. An ASAE Monograph, No.3, ASAE, 2950 Niles Rd. St. Joseph MI, USA.

Hills, D., and Y. Gu 1989 . Sprinkler volume mean droplet diameter as a function of pressure. Transactions of the ASAE 32 (2) : 471-476.

Ismail, S.M. 1986. Kinetic energy of water droplets at terminal velocity under fixed and revolving sprinkler. Misr J. Ag. Eng. ,3 (4): 43-57.

Jiusheng Li and Hiroshi Kawano, 1995. Simulating Water-Drop Movment From Noncircular Sprinkler Nozzles. J. Irrig. Drain. Div. ASCE 121 (2): 152-185. 
Jiusheng Li, Kawano H. and Yu, K. 1994. Droplet size distributions from different shaped sprinkler nozzles. Transactions of the ASAE 37(6): 18711878

Kincaid, D. C., K. H. Solomon, and J. C. Oliphant. 1996. Drop size distributions for irrigation sprinklers. Transactions of the ASAE 39 (3): 839-845.

Kohl, R. A. 1974 . Drop size distribution from medium-size agricultural sprinklers. Transactions of the ASAE 17 (4): 690-693.

Nawaby, A. S. 1970 . A method of direct measurement of spray droplet in an oil path. J. Agric. Engr. Res. 15(2): 182-184.

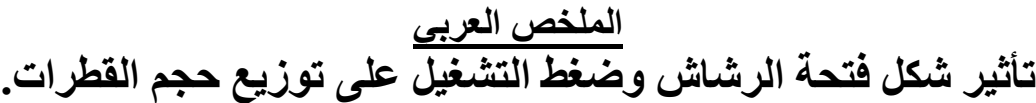

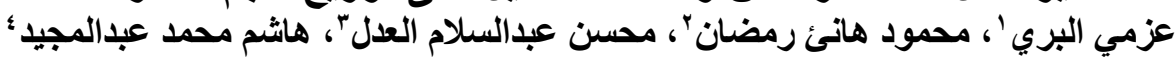

لتوزيع أحجام القطر ات أهمية في الحصول على الانتظامية حيث تُزيد القطرات ذات الألات الحجام الصغيرة

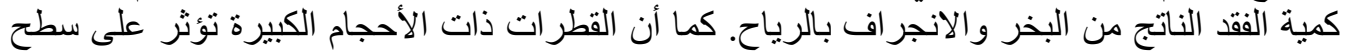

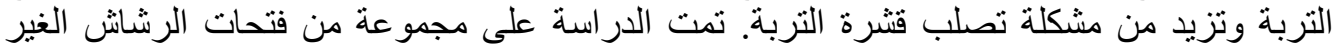

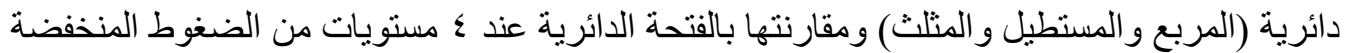

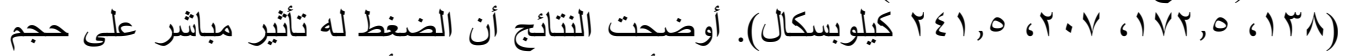

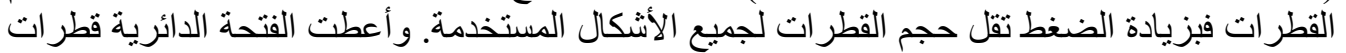

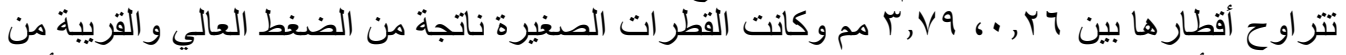

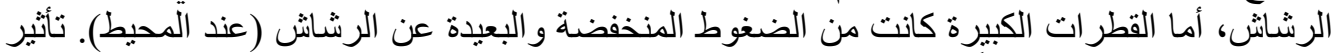

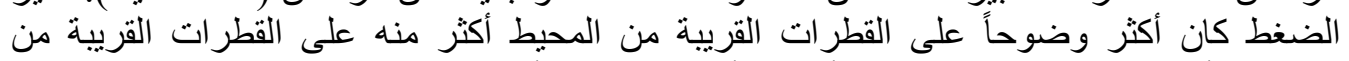

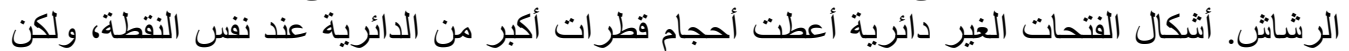

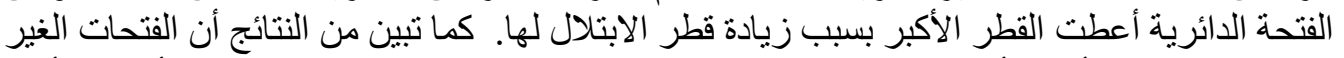

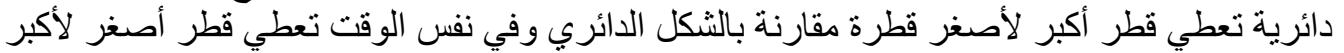

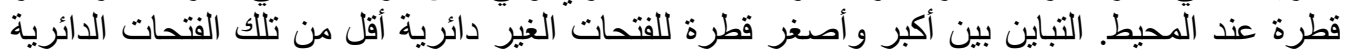

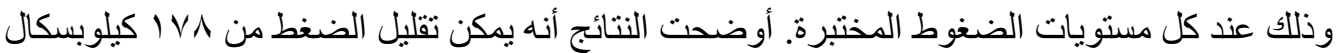

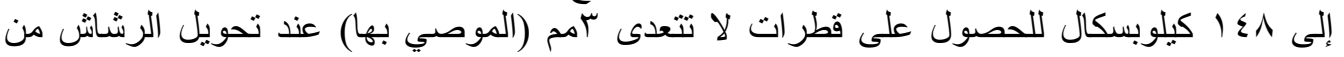

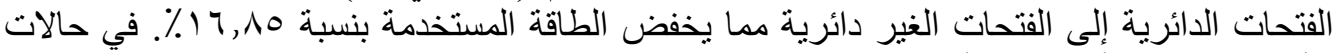

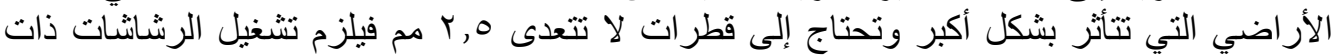

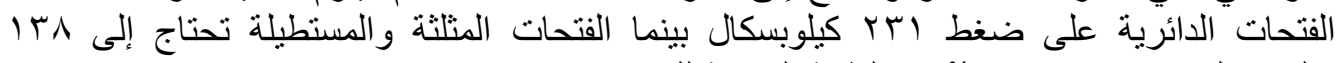

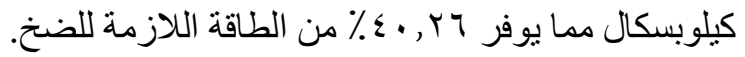

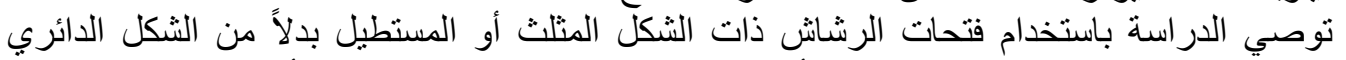

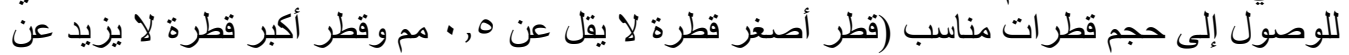
r مم) وذللك عند التشغيل على ضنغوط منخفضة لتوفير الطاقة اللازمة للتشغيل.

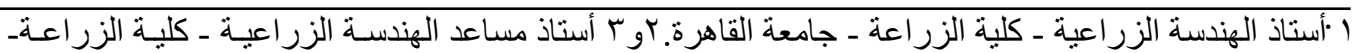

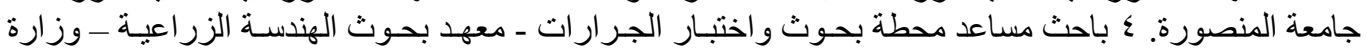
الزراعة 